\title{
Hitting the target with lung perfusion
}

\author{
Jason M. Gauthier, MD, ${ }^{\mathrm{a}}$ Varun Puri, MD, ${ }^{\mathrm{a}}$ and Daniel Kreisel, MD, PhD ${ }^{\mathrm{a}, \mathrm{b}}$
}

\footnotetext{
From the ${ }^{\mathrm{a}}$ Division of Cardiothoracic Surgery, Department of Surgery, and ${ }^{\mathrm{b}}$ Department of Pathology and Immunology, Washington University in St Louis School of Medicine, St Louis, Mo.

Disclosures: Dr D.K. serves on the Scientific Advisory Board of Compass Therapeutics. All other authors have nothing to disclose with regard to commercial support.

Received for publication Aug 3, 2017; accepted for publication Aug 8, 2017.

Address for reprints: Daniel Kreisel, MD, PhD, Department of Pathology and Immunology, Washington University School of Medicine, Campus Box 8234, 660 S Euclid Ave, St Louis, MO 63110 (E-mail: kreiseld@wustl. edu).

J Thorac Cardiovasc Surg 2017;154:1821-2

$0022-5223 / \$ 36.00$

Copyright (C) 2017 Published by Elsevier Inc. on behalf of The American Association for Thoracic Surgery http://dx.doi.org/10.1016/j.jtcvs.2017.08.009
}

Expansion of the donor lung pool may reduce the waitlist mortality for prospective pulmonary transplant recipients. At the present time, most lungs that are transplanted worldwide are obtained via donation after brain death. In an effort to expand the donor pool, some programs have developed algorithms to use lungs donated after circulatory death (DCD). Controlled DCD is defined as the planned withdrawal of life support in donors who do not meet criteria for brain death, whereas uncontrolled DCD involves urgent procurement following unplanned cardiac arrest. Recent studies have shown that short- and long-term outcomes after transplantation of controlled DCD lungs are not inferior to those after transplantation of donation after brain death lungs. ${ }^{1}$ Nevertheless, such organs are only infrequently used due to concerns over organ quality given the warm ischemia inherent to the process. Moreover, only a few centers have reported successful transplantation of lungs that were recovered after uncontrolled DCD. ${ }^{2}$ Over the past decade, ex vivo lung perfusion (EVLP) has been used to assess lungs deemed marginal for transplantation and some have advocated the routine use of this technology for DCD lungs.

In this issue, Charles and colleagues ${ }^{3}$ from The University of Virginia report the results of an elegant preclinical study examining the short-term influence of EVLP on lung graft function in a porcine model of uncontrolled DCD with prolonged warm ischemia. The authors demonstrate that EVLP alone yields superior results compared with cold preservation. Furthermore, the addition of an adenosine $\mathrm{A} 2 \mathrm{~B}$ receptor antagonist to the ex vivo lung perfusate improves dynamic lung compliance, decreases expression of interleukin-12 and reduces neutrophilic graft infiltration when compared with EVLP alone. These observations extend this group's previous findings regarding the effects of targeting adenosine receptors in attenuating pulmonary ischemia reperfusion injury. ${ }^{4}$ Moreover, others have demonstrated that EVLP can be used as a platform to administer pharmacologic

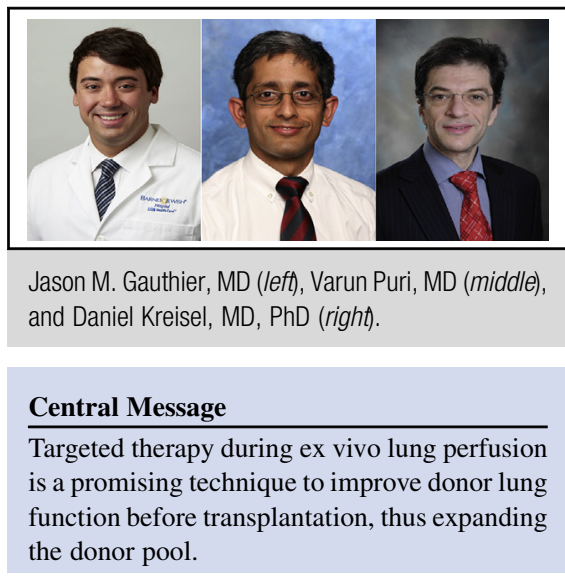

See Article page 1811. agents to donor lungs. Finally, the study by Charles and colleagues $^{3}$ supports the notion that targeting the local microenvironment of the pulmonary graft provides a rational approach to improving outcomes after lung transplantation, as we and others have shown that the lung provides a suitable environment for the interaction of immune cells. ${ }^{5}$

Preliminary reports have demonstrated the value of using EVLP in the evaluation of human lungs from uncontrolled DCD. ${ }^{6}$ The study by Charles and colleagues ${ }^{3}$ may provide further impetus to consider transplanting lungs obtained from uncontrolled DCD. It is important to point out that controlled DCD lungs should not be regarded as marginal organs, and, therefore, should not be routinely subjected to EVLP. ${ }^{7}$ More importantly, EVLP will allow for targeted pharmacologic treatments that improve graft function, as demonstrated by Charles and colleagues. ${ }^{3}$ As we gain a better understanding of the cellular and molecular pathways that contribute to failure of lung grafts, we will be able to administer therapeutic agents during EVLP. One can envision that targeted therapy during EVLP will lead to improved function even in lungs that are not considered marginal based on current criteria.

\section{References}

1. Krutsinger D, Reed RM, Blevins A, Puri V, De Oliveira NC, Zych B, et al. Lung transplantation from donation after cardiocirculatory death: a systematic review and meta-analysis. J Heart Lung Transplant. 2015;34:675-84.

2. Domínguez Gil B, Haase Kromwijk B, Van Leiden H, Neuberger J, Coene L, Morel P, et al. Current situation of donation after circulatory death in European countries. Transpl Int. 2011;24:676-86.

3. Charles EJ, Mehaffey JH, Sharma AK, Zhao Y, Stoler MH, Isbell JM, et al Lungs donated after circulatory death and prolonged warm ischemia are transplanted successfully after enhanced ex vivo lung perfusion using 
adenosine A2B receptor antagonism. J Thorac Cardiovasc Surg. 2017;154: 1811-20.

4. Huerter ME, Sharma AK, Zhao Y, Charles EJ, Kron IL, Laubach VE. Attenuation of pulmonary ischemia-reperfusion injury by adenosine A2B receptor antagonism. Ann Thorac Surg. 2016;102:385-93.

5. Gelman AE, Li W, Richardson SB, Zinselmeyer BH, Lai J, Okazaki M, et al. Cutting edge: acute lung allograft rejection is independent of secondary lymphoid organs. J Immunol. 2009;182:3969-73.
6. Moradiellos F, Córdoba M, Merlo P, Iranzo R, Diaz G, Garcia-Gallo C, et al. First lung transplants using controlled and uncontrolled DCD lungs evaluated with OCS-Lung Portable Exvivo Perfusion System. J Heart Lung Transplant. 2014;51:S4.

7. van Suylen V, Luijk B, Hoek RAS, van de Graaf EA, Verschuuren EA, Van De Wauwer C, et al. A multicenter study on long-term outcomes after lung transplantation comparing donation after circulatory death and donation after brain death. Am J Transplant. 2017;39:e175. 